\title{
Dispositivos Móveis Em Sala De Aula: \\ Uma Jornada Por Três Mundos Da Matemática
}

\section{Mobile Devices In Classrooms: A Journey Through Three Worlds Of Mathematics}

\author{
Rosana Nogueira de Lima* \\ Universidade Anhanguera de São Paulo - (UNIAN)
}

\begin{abstract}
Resumo
Neste artigo, apresentamos um estudo sobre a utilização de dispositivos móveis em sala de aula, para o aprendizado do Sistema de Numeração Decimal. Trabalhamos com 26 alunos de Licenciatura em Pedagogia de uma faculdade particular na região oeste da grande São Paulo, que resolveram cinco problemas (aditivos ou multiplicativos) com a utilização do Multibase, um aplicativo para a plataforma Android que simula o Material Dourado. Para a análise dos dados, utilizamos os Três Mundos da Matemática, considerando a possibilidade de lidar principalmente com os mundos corporificado e formal no Multibase. Os resultados indicam que o casamento entre tecnologia e o Material Dourado é uma ideia frutífera para o desenvolvimento de características formais do Sistema de Numeração Decimal.
\end{abstract}

Palavras-chave: Sistema de Numeração Decimal. Resolução de Problemas, Três Mundos da Matemática, Multibase

\begin{abstract}
In this paper, we present a research study on the use of mobile devices in classrooms for the learning of Decimal Number System. We worked with 26 pre-service elementary school teachers from a private college in the west of greater São Paulo area, who solved five (additive or multiplicative) problems by using Multibase, an Android app that simulates Base Ten Blocks. To analyse data, we used the Three Worlds of Mathematics, considering the possibility to deal specially with embodied and forma worlds in the app. Results indicated that the marriage between technology and Base Ten Blocs is a fruitful idea to develop forma characteristics of Decimal Number System.
\end{abstract}

Keywords/Palabras clave: Decimal Number System, Problem Solving, Three Worlds of Mathematics, Multibase

\footnotetext{
* Doutora em Educação Matemática pela Pontifícia Universidade Católica de São Paulo (PUC/SP). Professora e Pesquisadora da Universidade Anhanguera de São Paulo (UNIAN), São Paulo, São Paulo, Brasil. E-mail: rosananlima@gmail.com.
} 


\section{Introdução}

Ao estudar o ensino e a aprendizagem de conteúdos matemáticos considerando o uso de ferramentas tecnológicas, tais como os softwares GeoGebra e SimCalc (por exemplo Lima 2015; Lima, Bolite Frant \& Pereira, 2014), evidenciamos que esse uso possibilita novas transformações didáticas e cognitivas. Didáticas, pois muda-se a organização da sala de aula e a natureza das atividades propostas, trazendo um papel mais autônomo e ativo para o aluno. Cognitivas, pois uma Matemática diferente daquela gerada com o uso de papel e lápis emerge quando são utilizados softwares dinâmicos, que possibilitam a visualização de movimentos e a descoberta de propriedades matemáticas, ampliando as possibilidades de raciocínio, levantamento de conjecturas e desenvolvimento do aprendizado dos conteúdos envolvidos na atividade.

Levando esses resultados em consideração, buscamos avaliar também os dispositivos móveis como ferramentas tecnológicas úteis para o ensino e a aprendizagem, pois entendemos que essa tecnologia está presente na vida das pessoas em larga escala, em particular na das crianças que nasceram depois da criação da internet, dos dispositivos móveis e ainda da possibilidade de utilização da internet nesses dispositivos. É nossa crença que a sala de aula atual carece de novas ferramentas para o trabalho com os alunos, e nada melhor do que uma ferramenta que já é familiar a eles.

Nessa perspectiva, desenvolvemos um projeto de pesquisa que tem por objetivo analisar como práticas educacionais mediadas por diferentes recursos pedagógicos podem colaborar para o desenvolvimento da aprendizagem de conteúdos matemáticos que permeiam os anos iniciais do Ensino Fundamental. Para este artigo, trazemos, então, a discussão referente ao uso de um aplicativo para a plataforma Android, o Multibase, desenvolvido por Freitas (2004), inicialmente para computadores na plataforma Windows, e mais recentemente (Freitas, 2016), para uso com dispositivos móveis.

O Multibase simula o Material Dourado, recurso pedagógico desenvolvido pela médica e professora italiana Maria Montessori. Com ele, dentre outros conteúdos, pode-se ensinar o Sistema de Numeração Decimal e operações de adição e subtração com trocas e agrupamentos. Esse é o foco de nosso trabalho.

Para discutir a utilização do Multibase no ensino desses conteúdos, trabalhamos com um grupo de alunos de Licenciatura em Pedagogia, buscando analisar como esses futuros professores de anos iniciais do Ensino Fundamental trabalhariam com esse aplicativo, e qual a 
visão deles a respeito do trabalho com Multibase em sala de aula.

O trabalho foi realizado a partir da abordagem metodológica da Resolução de Problemas, considerando que ela promove o desenvolvimento de um pensar autônomo e do raciocínio matemático.

\section{Um Casamento Entre O Material Dourado E A Tecnologia: O Aplicativo Multibase}

No início do século XIX, Maria Montessori, uma médica e educadora italiana, desenvolveu alguns materiais manipulativos para o ensino de Matemática (Freitas, 2004). Ela acreditava que uma criança deveria trabalhar com os sentidos, e perceber sozinha possíveis erros e como superá-los. Dentre os materiais que desenvolveu, está o Material Dourado, que tem por objetivo principal que crianças aprendam o Sistema de Numeração Decimal Posicional.

O Material Dourado é formado por cubinhos que representam unidades, barras formadas por 10 cubinhos, que representam dezenas, placas formadas por 10 barras, que representam centenas e cubos grandes, formados por 10 placas, que representam milhares (Figura 1).

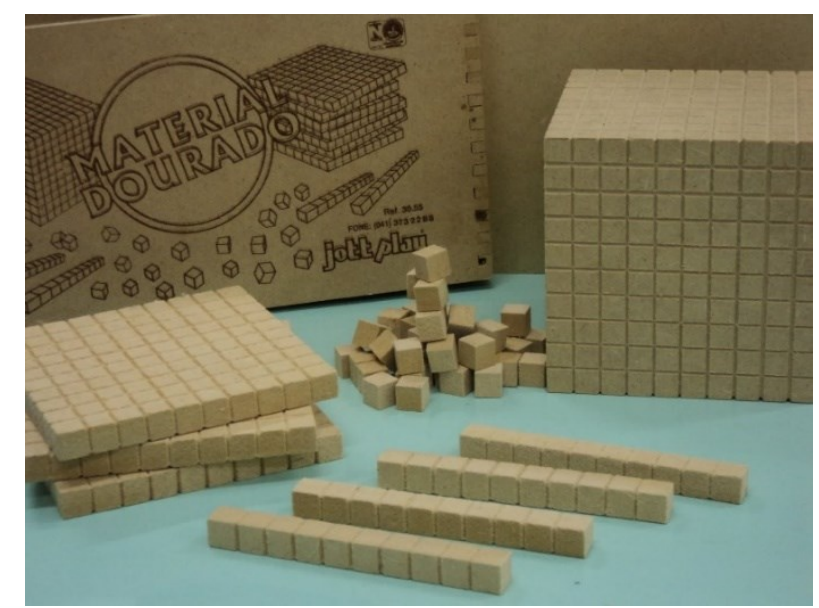

Figura 1: Material Dourado

Fonte: Acervo Pessoal

O trabalho com esse material permite, antes de se introduzir algoritmos das operações, que os alunos compreendam as trocas do Sistema de Numeração Decimal, isto é, que dez cubinhos (unidades) devem ser trocados por uma barra (uma dezena) e que dez barras devem ser trocadas por uma placa (uma centena). Essas trocas são essenciais para que se compreenda que nosso sistema é posicional. 
Para potencializar a utilização do Material Dourado, Freitas (2004) criou o Multibase, um ambiente computacional, que simula esse material. Nele, encontram-se as mesmas peças do Material Dourado, que podem ser arrastadas para a tela do computador, e também representam unidades, dezenas, centenas e milhares. Com ele, é possível ir além do uso do Material Dourado porque ele permite que o aluno continue uma atividade iniciada anteriormente, que sejam usadas cores nas peças, que o professor possa acompanhar as atividades feitas pelos alunos individualmente, e que bases diferentes da 10 sejam trabalhadas.

Após o estudo dessa versão, e com a possibilidade de utilização de aplicativos em dispositivos móveis, foi desenvolvida uma nova versão do Multibase, para a plataforma Android (Freitas, 2016), com as mesmas possibilidades do ambiente computacional. Na Figura 2 apresentamos a tela do Multibase com peças que foram arrastadas para a tela do painel liso, representando o número 1325.

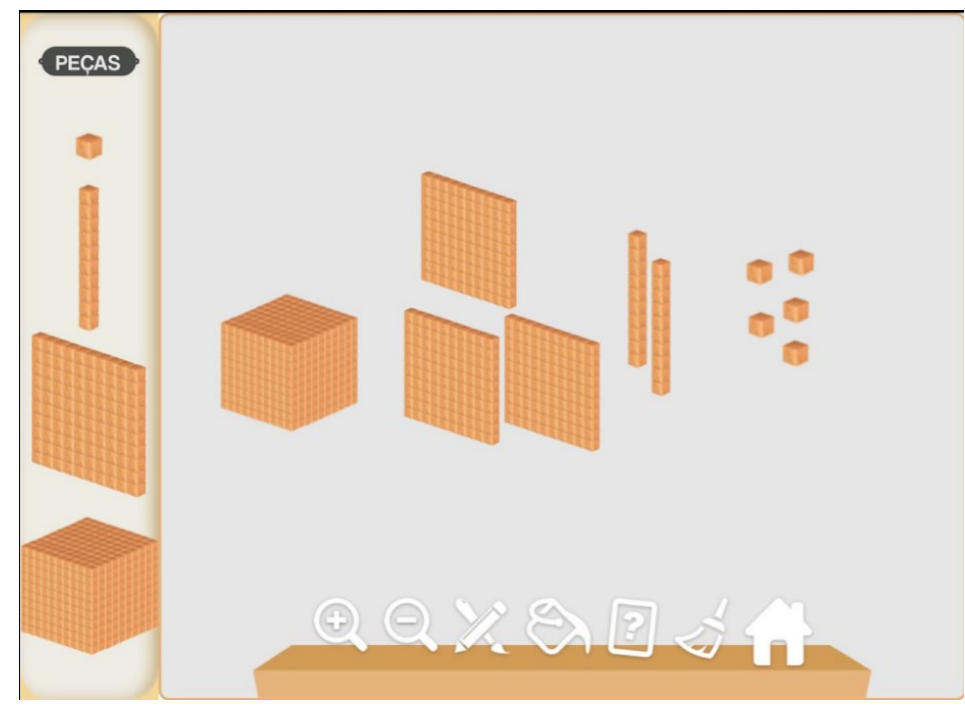

Figura 2: Tela do Multibase com a representação do número 1325 Fonte: Acervo Pessoal

Com o Multibase, é possível, também, trabalhar com o painel do Quadro Valor Lugar (QVL). Ao utilizar este painel, as peças devem ser colocadas na coluna adequada. Ao tentar posicionar, por exemplo, uma barra na coluna das unidades, o aplicativo emite uma mensagem de “Essa peça não pode ser colocada nesse painel, tente outro" (Figura 3). 


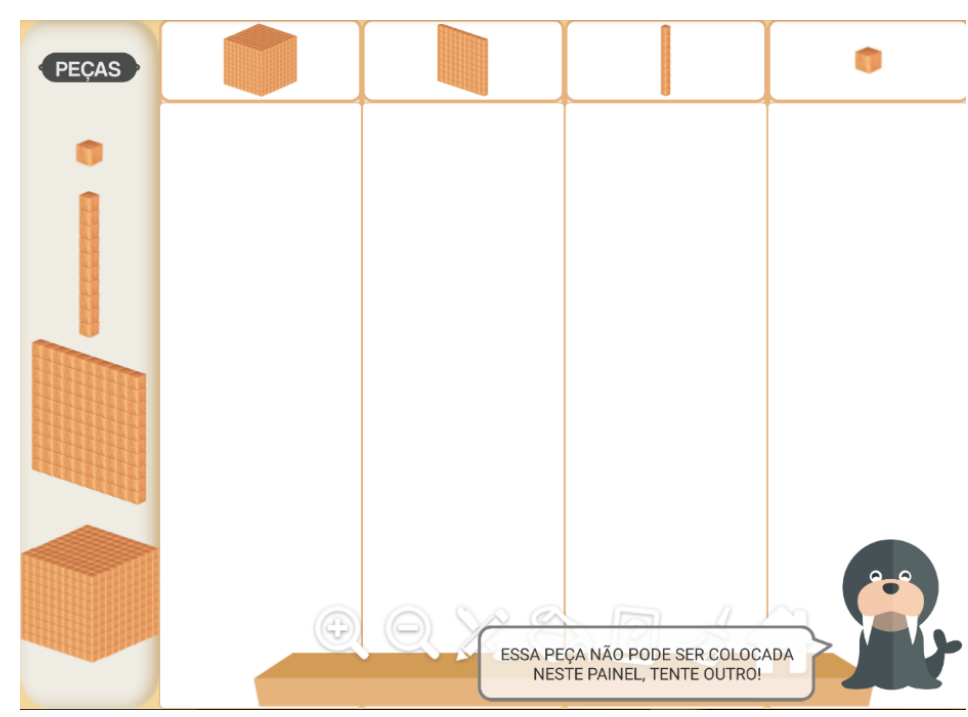

Figura 3: Mensagem de erro de posicionamento da peça no painel QVL

Fonte: Acervo Pessoal

Para discutir as trocas, por exemplo, de unidades para dezena e vice-versa, o Multibase possui duas ferramentas. Uma delas é o agrupamento. Ao obter-se dez cubinhos (dez unidades), é possível circulá-los com o dedo para formar uma barra (uma dezena). Da mesma forma, se precisarmos transformar uma dezena em 10 unidades, basta segurarmos a barra com o dedo e sacudi-la, que ela se transformará em dez cubinhos. Tais ferramentas são essenciais para que o aluno possa compreender as operações de adição e subtração com números maiores que 10.

Por exemplo, para resolver o problema da Figura 4, pode-se utilizar o Multibase para agrupar dez das 15 unidades obtidas pela a adição das unidades 6 e 9, para formar uma dezena, que será adicionada às 10 dezenas que já lá estão.

Cláudio tem 86 bolinhas de gude. Se ele ganhar outras 29 bolinhas, com quantas bolinhas vai ficar?

Figura 4: Problema aditivo com agrupamento

Fonte: Acervo Pessoal

No Multibase, esta ação é realizada circulando-se com o dedo as 10 unidades, o que resulta em uma barra. Ainda, é possível agrupar 10 das 11 dezenas para obter-se uma centena (Figura 5), que também é obtida circulando-se as dezenas com o dedo. 


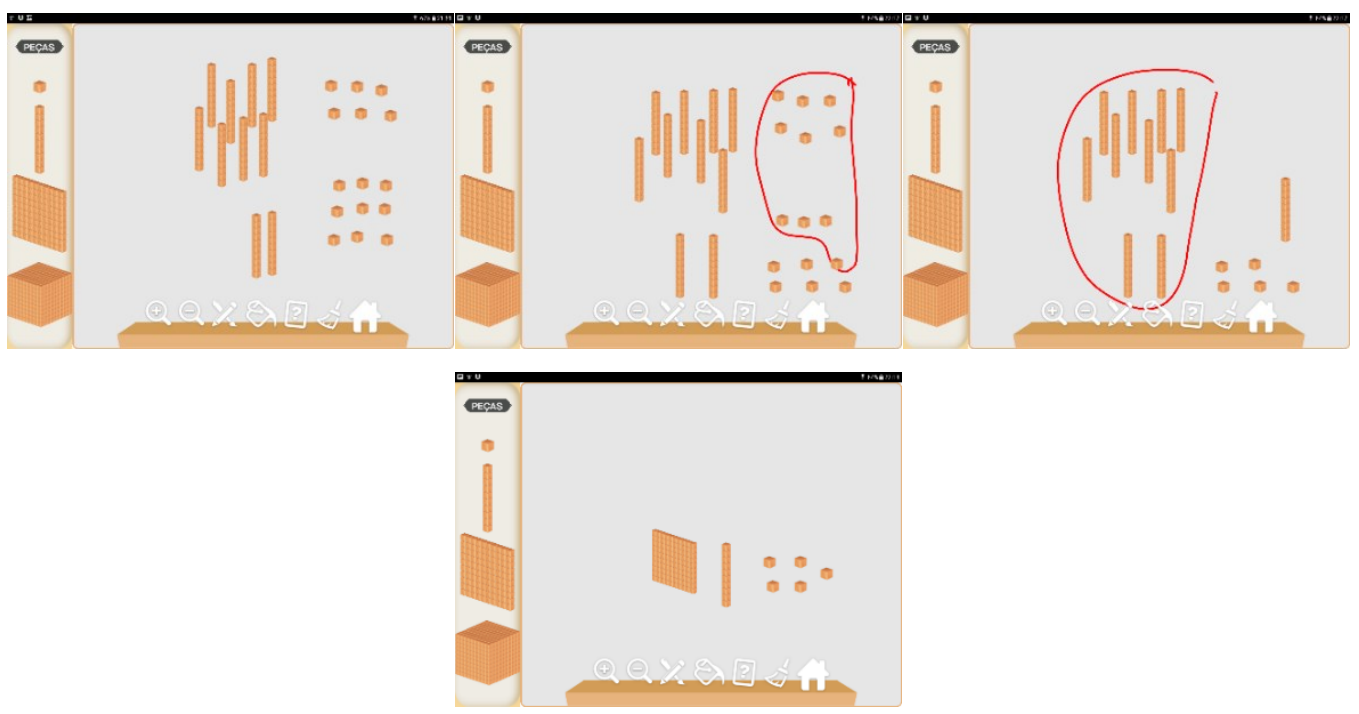

Figura 5: Agrupamentos para resolver o problema das bolinhas de gude Fonte: Acervo Pessoal

Já para resolver o problema da Figura 7: Agrupamentos para resolução do problema envolvendoFigura 6, que envolve uma subtração, isto é, tirar 67 de 84, é preciso desagrupar uma das 8 dezenas para ficar com 14 unidades e poder subtrair 7 delas.

Em um jogo de basquete, a equipe A venceu a equipe B por 84 a 67. Qual a diferença de pontos entre as duas equipes?

Figura 6: Problema aditivo

Fonte: Acervo Pessoal

No Multibase, a ação de retirar é realizada arrastando-se os cubinhos para a lixeira. No caso do exemplo, 7 cubinhos são arrastados, restando outros 7. Em seguida, arrastamos seis barras para a lixeira, isto é, subtraímos 6 dezenas das 7 restantes, obtendo uma barra e sete cubinhos, isto é, 17 pontos de diferença entre as duas equipes (Figura 7).

O Multibase não é o único aplicativo que simula o Material Dourado. Entretanto, a diferença entre ele e outros é que, com ele, pode-se utilizar diferentes bases, de 2 a 16, todas a partir das peças do Material Dourado. Dessa forma, podemos trabalhar ideias presentes no Sistema de Numeração Decimal em diferentes bases. Podemos, também, dar ao professor a oportunidade de compreender dificuldades que crianças têm ao aprender esse Sistema, apresentando a ele uma atividade que deve ser resolvida em uma base que não lhe é usual. 


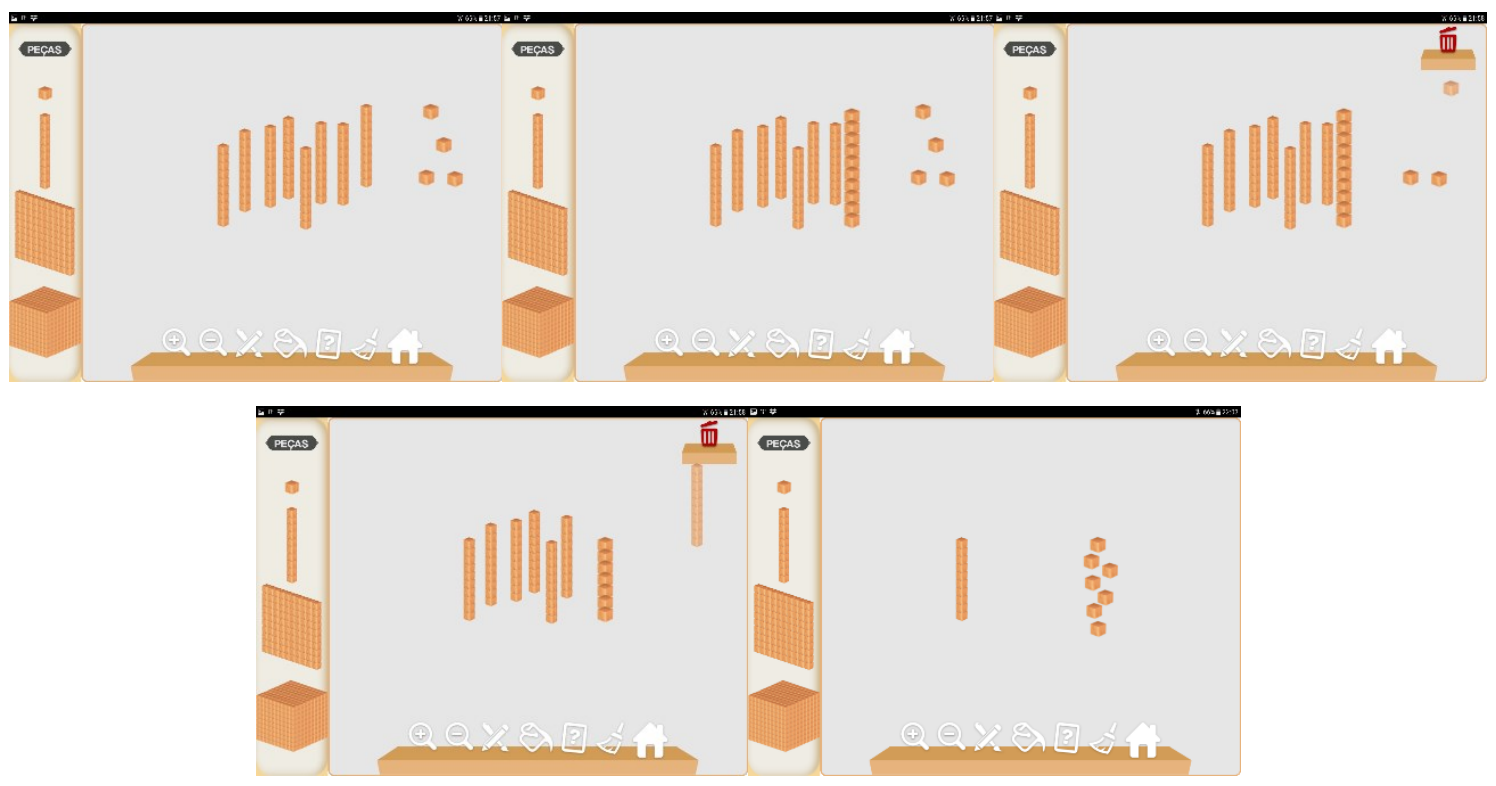

Figura 7: Agrupamentos para resolução do problema envolvendo

Fonte: Acervo Pessoal

Nossa escolha pela utilização do Multibase se deve a alguns fatores. Inicialmente, porque a compreensão do Sistema de Numeração Decimal e das Operações Aritméticas é essencial para o desenvolvimento de qualquer conceito matemático pelo aluno. Algumas pesquisas, como a de Costa \& Pavanello (2015), evidenciam as dificuldades que professores têm de ensinar o Sistema de Numeração Decimal e as trocas envolvidas nas operações, as dificuldades que alunos têm de aprender essas ideias, e ainda que a utilização do Material Dourado pode colaborar para diminuir essas dificuldades.

Outro fator importante para a utilização do Multibase é que o aluno pode utilizar uma versão informatizada do Material Dourado onde quer que ele esteja, basta ter à mão um dispositivo móvel. Isso significa que ele poderá continuar aprendendo Matemática fora do horário escolar. Além disso, os dispositivos móveis são familiares às crianças atuais, e isso pode ser um incentivo ao uso do aplicativo, e, consequentemente, ao trabalho autônomo e à aprendizagem.

O dispositivo móvel também permite que o aluno utilize uma manipulação touchscreen (Bairral, 2013). Esse tipo de manipulação é diferente do uso do mouse, por exemplo, porque ela permite que o aluno possa "tocar" nos objetos com os quais trabalha, numa relação muito próxima, no caso do Multibase, ao Material Dourado físico.

Finalmente, esses elementos disponíveis no Multibase proporcionam, ao aluno que com ele aprende, uma jornada por características dos Três Mundos da Matemática, referencial teórico de nossa pesquisa, como descrevemos na próxima seção. 


\section{Os Três Mundos Da Matemática}

Para a análise dos dados coletados, utilizamos o quadro teórico dos Três Mundos da Matemática (Tall, 2013). De acordo com Tall (2013), existem pelo menos três diferentes tipos de desenvolvimento cognitivo em Matemática, e esses tipos de desenvolvimento cognitivo habitam Três Mundos da Matemática, o mundo conceitual corporificado, o mundo operacional simbólico e o mundo formal axiomático.

O mundo conceitual corporificado, que chamaremos de mundo corporificado, é o mundo das percepções e ações efetuadas sobre um objeto (físico ou mental). Nesse mundo, as propriedades de um objeto são observadas e compreendidas.

O mundo operacional simbólico, que chamaremos de mundo simbólico, é o mundo dos símbolos matemáticos usados para representar as ações efetuadas sobre objetos matemáticos. Esses símbolos podem ser vistos de maneira flexível tanto como o procedimento a ser efetuado, quanto como o resultado obtido a partir do desenvolvimento desse procedimento, que é o conceito. Dessa forma, os símbolos, neste mundo, podem ser vistos como a dualidade entre processo e conceito, que gera o que Gray e Tall (1994) chamam de proceito. Além disso, se um indivíduo compreende os símbolos como proceitos, ele tem o que Gray e Tall (1994) chamam de pensamento proceitual.

Finalmente, o mundo formal axiomático, que chamaremos de mundo formal, no qual axiomas, propriedades, definições e teoremas são usados para construir o corpo axiomático da Matemática. É importante notar que, ao se trabalhar com alunos de anos iniciais do Ensino Fundamental, não se trabalha a Matemática axiomaticamente. Essa ideia está presente em cursos superiores. Entretanto, em qualquer atividade matemática encontram-se características do mundo formal, pois um aluno não constrói conceitos matemáticos sem compreender as características formais dele.

De acordo com Tall (2013), para que um indivíduo possa fazer uma jornada por esses mundos e assim desenvolver o aprendizado de conceitos matemáticos, experiências anteriores de aprendizado são fundamentais. Assim, Lima e Tall (2008) chamaram essas experiências de "já-encontrados", e os definiram como "...um construto mental que um indivíduo usa em um dado momento, baseado em experiências que ele encontrou anteriormente.” (Lima \& Tall, 2008, p.6, tradução nossa).

Ao ter nas mãos uma situação que lhe é familiar, um indivíduo se põe a resolvê-la

\footnotetext{
${ }^{1}$ Em inglês: "met-befores".
} 
utilizando ideias que utilizou anteriormente e resultaram em sucesso. Assim ele evoca seus jáencontrados assumindo-os válidos para tal situação. Há casos em que o já-encontrado é realmente válido e é utilizado de maneira a obter sucesso. Quando isso ocorre, ele é chamado de já-encontrado colaborador ${ }^{2}$ (Tall, 2013). Se ele não é válido para a situação em que se usa, ele é um já-encontrado dificultador ${ }^{3}$ (Tall, 2013).

Já-encontrados facilitadores e dificultadores interferem no aprendizado de conceitos matemáticos. Um professor que os conhece pode preparar a intervenção didática de modo a proporcionar o uso de já-encontrados facilitadores pelo aluno, colaborando para que o aprendizado ocorra. Por outro lado, é possível aproveitar a influência de já-encontrados dificultadores justamente para criar debates e discussões de forma a enriquecer ainda mais esse aprendizado. Assim, entendemos que é de extrema importância que professores compreendam e conheçam os já-encontrados que podem surgir para que possam fazer suas próprias escolhas didáticas.

A nosso ver, este quadro teórico é adequado para nossa pesquisa tendo em vista que o aplicativo Multibase pode proporcionar uma jornada pelos Três Mundos da Matemática.

A interface do Multibase permite que o aluno que o usa trabalhe com características corporificadas, a partir do touchscreen do dispositivo, movimentando as peças pelo painel, e utilizando-as para representar quantidades. As ações de, por exemplo, circular 10 barras para agrupá-las em uma placa, bem como de "sacudir" uma barra para transformá-la em 10 cubinhos também são corporificadas.

Subjacente às próprias peças estão características do mundo formal, já que um cubinho representa uma unidade, uma barra é formada por 10 cubinhos e representa uma dezena, uma placa é formada por 10 barras e representa uma centena e um cubo grande é formado por 10 placas e representa um milhar. Em particular, a característica do painel de QVL de impedir que uma peça seja colocada na coluna incorreta é, também, parte do mundo formal.

Finalmente, depois que o aluno já trabalhou com o Material Dourado físico e também com o Multibase, e está familiarizado com as ideias do Sistema de Numeração Decimal e de trocas, faz parte do trabalho do professor relacioná-las aos símbolos do mundo simbólico, apresentando, por exemplo, o algoritmo da adição, observando as trocas e agrupamentos, e que o chamado "vai um", de fato é uma dezena (ou ordem acima da adicionada) que se deve adicionar.

\footnotetext{
${ }^{2}$ Em inglês: "Supportive met-before".

${ }^{3}$ Em inglês: "Problematic met-before".
} 


\section{O Uso Do Multibase Em Sala De Aula}

Buscando atingir nosso objetivo de analisar como práticas educacionais mediadas por diferentes recursos pedagógicos podem colaborar para o desenvolvimento da aprendizagem de conteúdos matemáticos que permeiam os anos iniciais do Ensino Fundamental, iniciamos nossos estudos a partir de uma discussão com futuros professores desse nível de escolaridade.

Trabalhamos com um grupo de 26 alunos de $4^{\circ}$ semestre de Licenciatura em Pedagogia de uma Faculdade Particular localizada na zona oeste da grande São Paulo. Esses alunos tinham, em um mesmo dia letivo, as disciplinas de Fundamentos da Matemática e Práticas de Ensino de Matemática. Ambos os professores dessas disciplinas entenderam que seria pertinente a discussão que pretendíamos propor, e, com o consentimento do coordenador do curso e da direção da Faculdade, utilizamos esse período para o desenvolvimento de atividades utilizando o aplicativo Multibase.

Para que os alunos vivenciassem o trabalho com operações aritméticas, escolhemos utilizar a abordagem metodológica da Resolução de Problemas. Entendemos que o ensino via resolução de problemas (Schroeder \& Lester, 1989) permite que o aluno construa o conhecimento a partir de uma situação que lhe é desconhecida, e que ele precisa resolver. Com essa abordagem, o aluno acaba por tomar para si o problema, e empenha-se a resolvê-lo.

Além disso, Cybis e Lima (2015) evidenciaram que resolver problemas pode colaborar para o entendimento de conceitos subjacentes às operações aritméticas. Na pesquisa, foi utilizada uma Ficha de Resolução de Problemas, que guia o aluno a levantar dados relevantes do problema, refletir sobre os conhecimentos que podem ser usados na resolução e sobre a resposta a ser dada ao problema. A Ficha permite, ainda, que os alunos em processo de resolução de problemas discutam entre si sobre a validade da resolução apresentada. Resultados da pesquisa evidenciam a compreensão, por parte dos alunos participantes (de $5^{\circ}$ ano do ensino fundamental), de elementos essenciais para a resolução de um problema, bem como de conceitos do campo conceitual multiplicativo, tema dos problemas a eles apresentados. Mesmo sem a utilização da Ficha de Resolução de Problemas, conjecturamos que resultados similares podem ser obtidos com a resolução de problemas aditivos.

Assim, os alunos de Licenciatura em Pedagogia trabalharam em grupos para resolver cinco problemas, três aditivos e dois multiplicativos. Os problemas trabalhados foram extraídos ou adaptados de Freitas (2004). Exemplos dos problemas apresentados a eles podem ser vistos na Figura 4 e na Figura 6. Vale enfatizar que procuramos problemas aditivos nos quais seria 
necessário realizar transformações de unidades para dezena e vice-versa, pois essas situações são as de maior interesse ao se trabalhar o Sistema de Numeração Decimal. No que se refere aos problemas multiplicativos, eles podem ser trabalhados no Multibase como adição de parcelas iguais.

Tendo os alunos trabalhado os problemas em grupo, passamos a discuti-los com a sala toda, projetando a tela de um tablet, no qual reproduzíamos as sugestões de resolução que os próprios alunos nos apresentavam.

Depois de discutidos os problemas, os alunos trabalharam utilizando uma base diferente da 10 à escolha de cada grupo. Essa atividade tinha por objetivo que o futuro professor passasse por dificuldades similares às dos alunos de anos iniciais do Ensino Fundamental ao terem um primeiro contato com o Sistema de Numeração Decimal. Sendo uma base não usual, ele poderia ter dificuldades em entender como e quando fazer as trocas. Para isso, solicitamos que eles escolhessem uma base no Multibase, e cada integrante do grupo escolhesse uma operação a ser realizada nessa base.

Antes dessa atividade com base diferente da 10, fizemos uma discussão com o grupo todo sobre essa ideia, utilizando a base 4. Apresentamos alguns números, e solicitamos que os alunos falassem outros números para efetuarmos adições.

Os dados foram coletados por meio de protocolos escritos desses alunos. Além disso, solicitamos que eles baixassem nos celulares a serem usados o aplicativo Screencast para a plataforma Android. Similar ao software Camtasia para computadores na plataforma Windows, este aplicativo é gratuito e grava a tela do celular e o áudio ao redor do aparelho. Dessa forma, obtivemos também essas gravações dos participantes, e foi possível saber como resolveram os problemas com a utilização do Multibase e as conversas que tiveram durante a resolução. As discussões com a sala toda também foram gravadas por meio do aplicativo Screencast, instalado no tablet usado para a discussão com o grupo todo.

\section{Análise De Dados}

Devido a algumas dificuldades que tivemos para que os alunos baixassem os aplicativos necessários para a coleta de dados, acabamos por não obter gravações de todos os oito grupos formados pelos 26 alunos. Alguns não conseguiram baixar o aplicativo Screencast, e outros o fizeram, mas nem todos retornaram os arquivos para análise. Assim, para este artigo, apresentamos as telas e falas obtidas com um desses grupos, formado por três alunas, bem como 
a discussão realizada com a sala toda.

\subsection{Problemas Aditivos E Multiplicativos}

Nos protocolos escritos, os alunos apresentaram a resposta a cada problema, como o exemplo da Figura 8. Observamos que eles tiveram a preocupação de dar a resposta completa ao problema.

\section{Mário foi a uma livraria e gastou 37 reais dos 50 reais que possuía. Com quantos reais Mário ficou?}

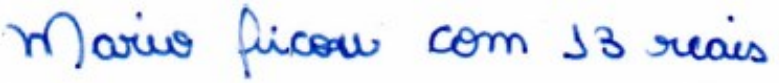

Figura 8: Resposta do grupo para um problema aditivo

Fonte: Acervo Pessoal

Para responder o primeiro problema, apresentado na Figura 6, que envolve a operação 84 - 67, as alunas utilizaram o painel QVL, e colocaram 8 barras e 4 cubinhos em suas respectivas colunas. Para efetuar a subtração, iniciaram "sacudindo" uma barra, pois perceberam a necessidade de transforma 4 em 14. Em seguida, elas arrastaram para a lixeira primeiro as 6 barras e depois os 7 cubinhos.

Durante essa execução, as alunas contaram as quantidades colocadas no painel ou retiradas dele. Para a colocação das 8 dezenas, elas contaram juntas: “dez, vinte, trinta, quarenta,...”, parecendo tratar as dezenas como unidades. Isso ficou evidente na fala de uma das alunas, Andréa ${ }^{4}$, ao tratar a retirada das 6 dezenas, pois ela pensou ser necessário transformar todas as barrinhas em cubinhos para excluir as 60 unidades, o que foi corrigido por Lúcia.

Andréa: Tem que desfazer um monte de barrinhas, então.

Lúcia: Não, pega sessenta e joga lá.

Helena: Tem que tirar sessenta e mais sete, e contar o que sobrou.

Andréa: Quantas ficaram?

Lúcia: Dez, onze, doze, treze, catorze, quinze, dezesseis, dezessete [fala o último número com mais ênfase].

Helena: Tá, e como faz para finalizar?

${ }^{4}$ Os nomes dos participantes foram modificados para garantir anonimato. 
Na Figura 9, apresentamos a tela do Multibase com o resultado do problema proposto.

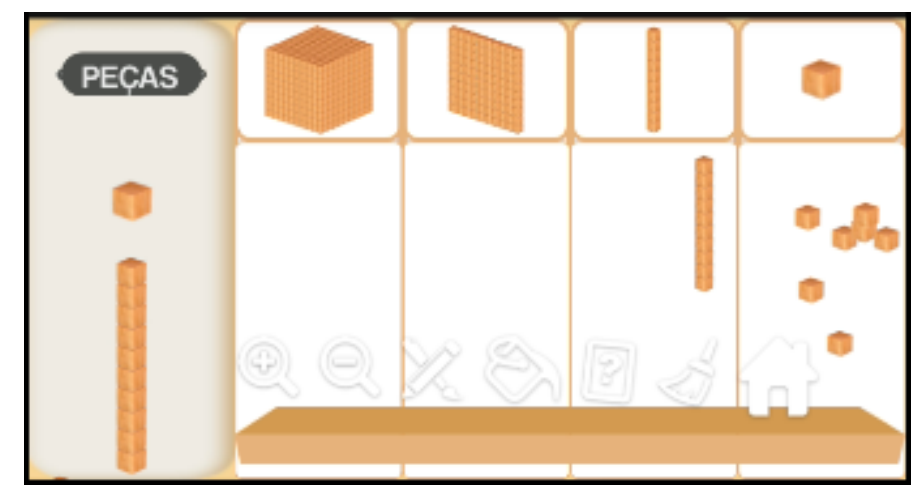

Figura 9: Resultado da operação $84-67$

Fonte: Acervo Pessoal

Para resolver o problema proposto, as alunas utilizaram a ideia de "tirar" uma quantidade de outra, que é uma característica corporificada para a operação de subtração. Isso foi feito deslizando-se as peças do painel QVL para a lixeira, também uma corporificação, nesse caso, relacionada ao aplicativo. As ideias de transformação da barra em cubinhos, isto é, de dezena para unidades é uma característica formal.

Ao resolverem o problema, Helena questionou: “Tá, e como faz para finalizar?". Entendemos que elas estavam com dificuldade de compreender como apresentar o resultado do problema no Multibase, não compreenderam que esta solução da Figura 9 já seria suficiente, talvez por desejar a utilização de características simbólicas para esse fim, como foi feito no protocolo apresentado na Figura 8. Quando a pesquisadora explicou que já haviam representado a solução, elas aceitaram e passaram para o próximo problema, que envolvia uma divisão.

No segundo problema resolvido pelo grupo, elas deveriam dividir 16 bombons para duas meninas, o que gerou o diálogo transcrito a seguir.

Helena: Mas aí, se você sacudir a barrinha inteira de 10, se passar dois para cá, e os outros oito vão para onde?

Lúcia: Boa pergunta!

Helena: Vamos continuar o problema. Tem dezesseis, agora eu tenho que dividir para duas. Andréa: Se eu desfizer essa barrinha, eu não posso só jogar duas para lá, porque aqui [na coluna das dezenas do painel QVL] vai ficar em zero, e as barrinhas vão ficar embaixo.

Lúcia: Como fazer?

Helena: Excluir as barrinhas. Joga tudo aqui. Transforma a barrinha de dezena em unidade.

Lúcia: Beleza, mas você vai dividir como, se é para dividir por dois?

Andréa: É. Vai para onde, essas barrinhas que é para dividir.

Helena: Não vai para lugar nenhum, vai ficar aqui. A gente conta e tem tanto para tanto.

Lúcia: Não o negócio tem que me dar um resultado aqui, igual ao outro. Eu tenho que contar depois. 
Andréa: Mas o resultado vai parecer aqui, é só a gente contar quantas serão para cada parte. Helena: Quantas barrinhas são no total? Dezesseis? Vai ficar oito em cima e oito embaixo? Andréa: Uma barrinha e dezesseis unidades.

Lúcia: Aquela hora ficou claro. Ficou uma barrinha de dez e de sete. Aí no caso tem que ser dois montinhos de oito. E vai dividir no mesmo bloco?

Andréa: É isso que eu quero saber.

Helena: Sim, no mesmo bloco, porque você não tem uma dezena para cada um.

Lúcia: Tá, e você vai colocar oito aqui e oito embaixo?

Andréa: Ué, pode ser.

Lúcia: Então faz aí.

Nesse diálogo, elas apresentam a transformação da dezena em unidades, para que possam dividir 16 por 2 , o que apresenta características formais sendo reveladas por ações corporificadas. Além disso, discutem como representar no painel do Multibase o resultado da divisão. No primeiro problema, Lúcia ficou satisfeita com a ideia de que as peças do Multibase na tela representavam a solução do problema. Para este segundo problema, ela teve dificuldades, pois as peças ficariam todas na tela, e não somente oito unidades do resultado final. Talvez, ainda interessada em características do mundo simbólico, Lúcia buscou o resultado na tela, o que foi resolvido pelas outras integrantes do grupo, deixando oito cubinhos no canto superior da tela e outros oito no canto inferior, como apresentado na Figura 10.

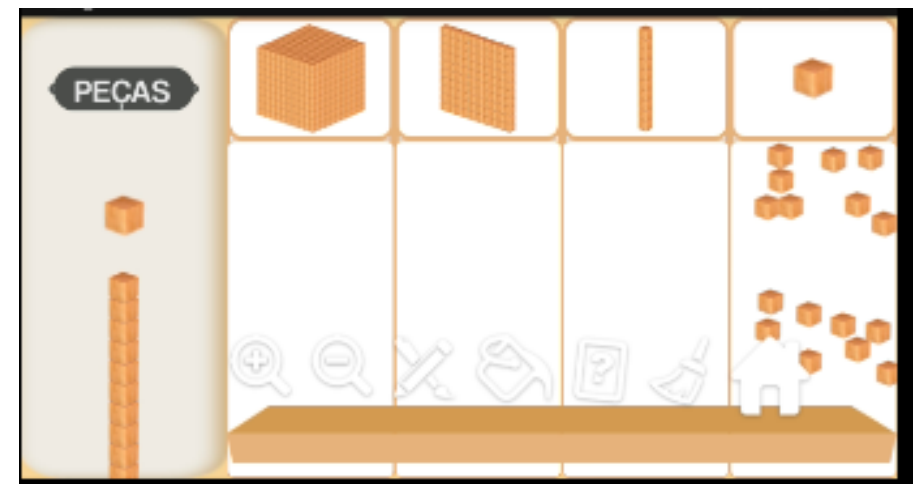

Figura 10: Resultado da divisão de 16 por 2 na tela do Multibase

Fonte: Acervo Pessoal

Durante a fala, Andréa, que estava manuseando o Multibase, acabou por fechar a tela que estavam usando, e iniciou novamente. Para recolocar as 16 unidades na tela, ela não quis "ter o trabalho" de quebrar novamente a barra em cubinhos, então começou a colocar os 16 cubinhos. Helena indagou "mas o seu aluno vai pensar isso?", e o restante do grupo acabou por convencer Helena a retomar a barra para a representação de 16 argumentando que os alunos diriam que 16 é uma dezena e seis unidades.

Essa discussão evidencia que as alunas iniciaram uma reflexão sobre a utilização do 
Multibase em sala de aula, e como o aluno se comportaria, ou como elas teriam que justificar suas ações a eles. Tais justificativas rementem a características formais das operações e trocas.

Para o problema apresentado na Figura 4, o grupo colocou primeiro 8 dezenas e 4 unidades no painel QVL, e depois mais 2 dezenas e 9 unidades, obtendo a tela como na Figura 11, e utilizando características corporificadas presentes no aplicativo.

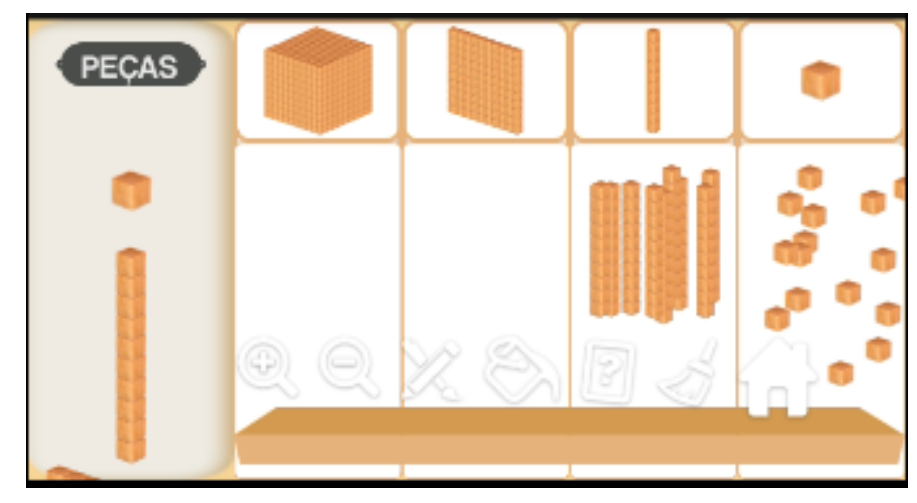

Figura 11: Tela do grupo para resolver a adição $84+29$

Fonte: Acervo Pessoal

Helena sugere: "Vamos contar?"

Mas Lúcia não concorda.

Lúcia: Tá, mas aqui, na minha opinião, tinha que pegar uma barrinha de dez e ir para lá. Como faz para virar barrinha de dez?

Andréa: É circular, assim, ó xiii [simulando um barulho de circular a tela].

Lúcia: É, circula dez,

Helena: Mas tem dez aqui? [apontando para a coluna das dezenas]

Andréa: Não, meu amor, aqui. [referindo-se à coluna das unidades]

Helena: Ah tá.

Andréa: Aqui tem cem. [na coluna das dezenas]

Lúcia: Circula dez unidades.

Andréa: Você colocou mais vinte, tem cem. Agora pode colocar tudo para cá, não pode? [diz isso circulando dez dezenas e obtém uma placa, como na Figura 12]

Helena: Agora vamos colocar para cá, já tem cem.

Lúcia: Aí você pega dez, circula dez para virar uma barrinha [Figura 12: Obtenção de uma centena

$$
\text { Fonte: Acervo Pessoal }
$$

].

Lúcia: Ficou quantas?

Andréa: Cento, e dez, um, dois, três, quatro, cinco, cento e quinze! Ehhhhh! 


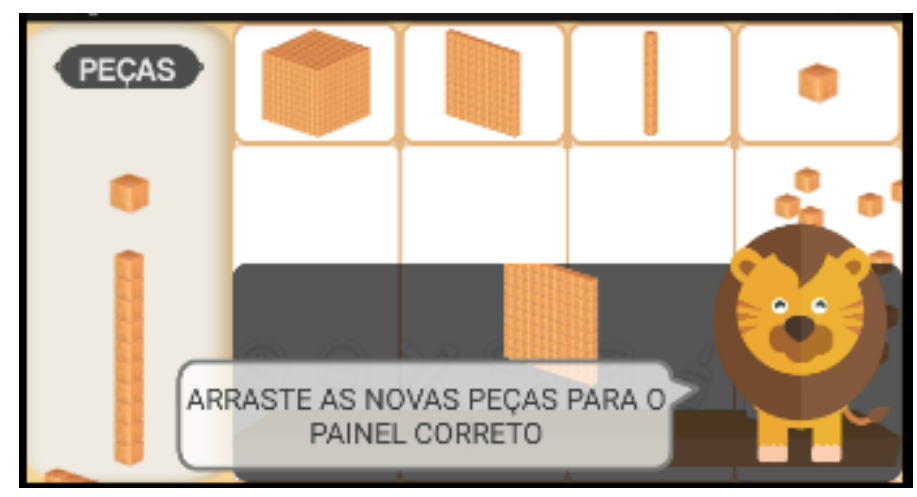

Figura 12: Obtenção de uma centena Fonte: Acervo Pessoal

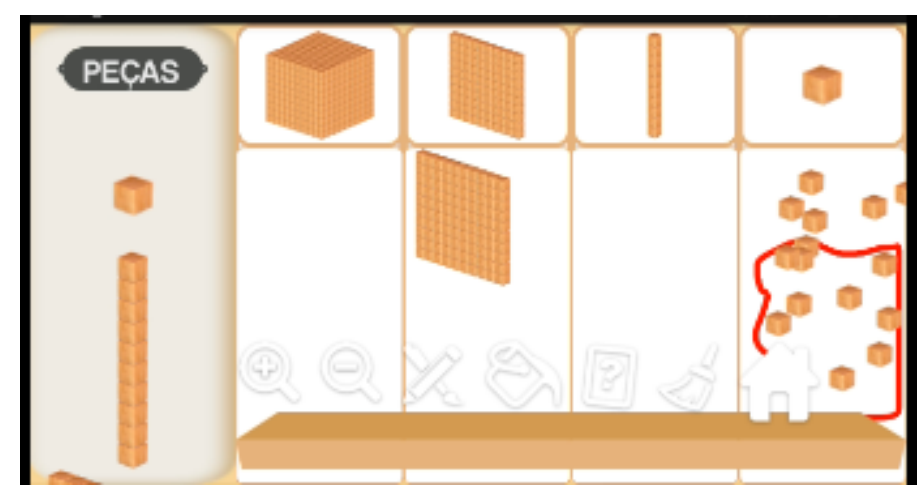

Figura 13: Circulando uma dezena

Fonte: Acervo Pessoal

Lúcia parece ter compreendido a utilização do Multibase e a ideia de transformações, característica do mundo formal. Ao invés de contar quantos cubinhos há na tela, ela sugere que se transforme dez cubinhos em uma barra. Antes de executar esta ação, Andréa, que percebeu a adição entre 8 dezenas e 2 dezenas, sugere que elas sejam transformadas em uma centena, e o faz utilizando características corporificadas de circular as peças e obtém a centena (Figura 12).

Por fim, 10 unidades são transformadas em uma centena (Figura 12: Obtenção de uma centena

\section{Fonte: Acervo Pessoal}

), e já é fácil contar como Lúcia pretendia.

O trabalho com a resolução de problemas no Multibase proporcionou que as alunas discutissem as possíveis transformações, observassem características formais das operações e as representasse de maneira corporificada. Também fizeram uma reflexão sobre como trabalhar esses elementos com futuros alunos.

Em seguida, passamos para a discussão de bases diferentes. 


\subsection{Trabalhando Com Bases Diferentes Da Usual}

Para que o futuro professor possa compreender as dificuldades que um aluno tem ao iniciar o aprendizado do Sistema de Numeração Decimal, solicitamos que ele trabalhasse com uma base diferente da 10, o que significa que ele também iniciaria o aprendizado de um sistema de numeração. Dessa forma, a atividade colocaria o futuro professor na posição do aluno que ele terá nos anos iniciais do ensino fundamental.

Nossa proposta foi a de que os alunos, nos mesmos grupos, escolhessem uma base diferente da 10 e selecionassem operações que exigem trocas para serem efetuadas. Para que compreendessem melhor a atividade, foi realizada uma discussão sobre bases, na qual trabalhamos com a base 4. Nessa discussão, fizemos, também, cálculos com o algoritmo da adição, explicando as trocas.

Ao passarmos para a discussão nos grupos, Andréa, Lúcia e Helena escolheram a base 5. O professor da turma estava conversando com elas, e sugeriu que elas usassem alguma base usual a elas. Durante a discussão sobre diferentes bases, o professor comentou que sete dias formam uma semana, e que isso poderia ser uma metáfora para a base 7. Assim, Helena disse "vamos pegar a base 7, que é semana".

Lúcia, aparentemente, não compreendeu o que deveria fazer para cumprir a atividade solicitada. Ela queria saber que tipo de adição deveria fazer. Andréa solicita a presença da pesquisadora.

Lúcia: Sete mais sete mais sete dá vinte e um. Vinte e um menos sete vai dar catorze. É isso? Andréa: Nós colocamos a base sete e estávamos pensando em trabalhar com a semana, sete dias.

Pesquisadora: Legal.

Andréa: Mas na adição, o que a senhora sugere? Vamos somar quatro semanas, que dá um mês, seria isso?

Pesquisadora: Pode ser.

Nessa primeira fala de Lúcia, vemos que ela não utilizou a base 7, pois estava fazendo operações na base 10, utilizando o número 7. Isso é indício de que ela pode não ter transferido as características formais que conhece da base 10 para utilizá-las na base 7 .

Considerando a ideia de Andréa, as alunas colocam quatro barras na tela, e as circulam, recebendo uma mensagem do aplicativo de que não é possível agrupar aquelas peças. Uma ação 
corporificada fez com que elas tivessem que refletir sobre características formais das bases.

Pesquisadora: É porque precisa de 7! Para ir para a outra ordem, precisa juntar 7, então o quatro do mês não funciona.

Andréa: Por causa da base que é sete. Tem que ser o dia da semana.

Pesquisadora: É. Na verdade a semana, ela só serve para unidade e para dezena.

Andréa: Entendi.

Apesar de Andréa ter afirmado que "entendeu", ela colocou sete barras no painel, circulou, conseguiu uma placa, mas não compreendeu o que aquela placa significa na metáfora utilizada. Ela perguntou algumas vezes às colegas qual era o significado da placa, mas não obteve resposta. $\mathrm{O}$ grupo então sacudiu a placa, levou três barras para o lixo, e ficou com quatro barras, que Andréa chamou de "um mês", e Helena de "vinte e oito dias". Com isso, elas encerram a atividade.

Aparentemente, o grupo não compreendeu a proposta da atividade. As alunas não elaboraram operações com números representados na base 7 que envolvessem trocas para serem efetuadas. $\mathrm{O}$ interesse delas era obter uma relação entre a metáfora utilizada e as unidades, as “dezenas" e as "centenas" na base 7. Talvez, o pouco tempo de discussão e a ausência dessa relação entre a metáfora da semana e a "centena" na base 7 tenham sido fatores que as impediram de continuar. Ainda assim, observamos as tentativas de conexões entre características corporificadas e formais durante as discussões do grupo.

No que segue, tecemos nossas conclusões a respeito do trabalho realizado.

\section{Conclusões}

Neste artigo, apresentamos um recorte de um projeto de pesquisa que tem por objetivo analisar como práticas educacionais mediadas por diferentes recursos pedagógicos podem colaborar para o desenvolvimento da aprendizagem de conteúdos matemáticos que permeiam os anos iniciais do Ensino Fundamental. Nesse recorte, buscamos analisar como alunos de Licenciatura em Pedagogia, futuros professores de anos iniciais do Ensino Fundamental, trabalhariam com o aplicativo Multibase para discussão do Sistema de Numeração Decimal, e qual a visão deles a respeito do trabalho com esse aplicativo em sala de aula.

Para isso, utilizamos a abordagem de resolução de problemas. Levamos cinco problemas para esses alunos, e eles trabalharam em grupos para resolvê-los com o auxílio do Multibase. Em seguida, discutiram, também, o uso de bases diferentes da 10. 
Inicialmente, observamos que o uso de problemas para a discussão das trocas e agrupamentos mostrou-se um veículo adequado, pois colaborou para que os alunos tivessem interesse em resolver as operações e desenvolvessem suas ideias.

Os resultados obtidos evidenciam que o aplicativo Multibase possibilita que quem o usa relacione características corporificadas a características do mundo formal. Isso pode ser realizado, pois representar unidades e dezenas com peças, circulá-las para agrupá-las em elementos de uma ordem superior, e "sacudi-las" para transformá-las em uma ordem inferior são características do mundo corporificado que só podem ser realizadas com a compreensão de características formais de, a cada 10 unidades transformarem-se em uma dezena, ou que uma centena pode ser separada em 10 dezenas. Esses elementos foram compreendidos naturalmente pelas alunas do grupo analisado.

Além disso, observamos que características do mundo formal para o trabalho com bases diferentes, mesmo sendo compreendidas para a base 10, não parecem ser naturalmente transferidas para uma base não usual, isto é, observamos indícios de que os já-encontrados da base 10 podem não ser suficientes para que ocorra um entendimento de outras bases. Além disso, considerando que as alunas do grupo analisado não trabalharam o número na base 7 , mas sim na base 10, por exemplo quando disseram que "Sete mais sete mais sete dá vinte e um. Vinte e um menos sete vai dar catorze", ao invés de pensar em uma barra de 7 mais outra barra de 7 é igual a duas barras de 7, observamos que os já-encontrados da base 10 podem até mesmo ser utilizados de maneira dificultadora.

Conjecturamos que trabalhar com bases diferentes da 10 com alunos na Educação Infantil ou mesmo nos anos iniciais do Ensino Fundamental pode ser um meio de evitar jáencontrados dificultadores mais tarde. Essa ideia pode ser explorada pelo professor em suas escolhas didáticas. Talvez, as trocas e agrupamentos em outras bases podem se tornar aencontrar favoráveis para alunos nesses níveis de escolaridade compreendam a base 10 .

Características do mundo simbólico não foram muito evidenciadas neste trabalho, essencialmente por não terem sido extensamente exploradas nas atividades aplicadas. Ainda assim, vemos, em algumas falas de Lúcia, uma preocupação com o resultado obtido, o que nos remete ao uso de símbolos matemáticos que habitam o mundo simbólico. Eles foram trabalhados de forma não-usual a essas alunas, pois os símbolos foram representados por entes corporificados.

Por outro lado, na conversa com toda a sala, em que se discutiu o uso de outras bases, foram apresentados algoritmos de resolução de algumas operações, e evidenciou-se a 
preocupação desses alunos com o mundo simbólico. Entendemos que a transição de representações com peças do mundo corporificado para símbolos matemáticos do mundo simbólico se faz extremamente necessária, mas deve ser realizada após o entendimento, pelos alunos, dos agrupamentos e desagrupamentos realizados com Material Dourado físico, ou no Multibase. Para estudar nossas conjecturas a respeito, continuamos o desenvolvimento dessa pesquisa.

\section{Referências}

Bairral, M. A. (2013). Do Clique ao Touchscreen: novas formas de interação e de aprendizado matemático. 36 a Reunião Nacional da ANPEd. Goiânia/GO.

Costa, L. P., \& Pavanello, R. M. (2015). "Vai" e "Empresta": A relação entre o Conceito e o Procedimento, entre o Ensino e a Aprendizagem. Em R. Borba, \& G. Guimarães (Eds.), Pesquisa e Atividades para o Aprendizado Matemático na Educação Infantil e nos Anos Iniciais do Ensino Fundamental (pp. 192-213). Brasília, DF, Brasil: Sociedade Brasileira de Educação Matemática - SBEM.

Cybis, A. C., \& Lima, R. N. (2015). Entrada, Ataque e Revisão: uma abordagem para a resolução de problemas multiplicativos. 4o Simpósio Internacional de Pesquisa em Educação Matematica, (pp. 1825-1836). Ilhéus/BA.

Freitas, R. C. (2004). Um Ambiente para Operações Virtuais com o Material Dourado. Dissertação de Mestrado, Universidade Federal do Espírito Santo, Informática, Vitória.

Freitas, R. C. (2016). Aplicativo Multibase para tablets: Análise de uma de suas funcionalidades. Educação Matemática em Revista, 51, pp. 15-24. Acesso em 15 de novembro de 2016

Gray, E., \& Tall, D. O. (1994). Duality, Ambiguity and Flexibility: a proceptual view of simple arithmetic. The Journal for Research in Mathematics Education, 26(2), pp. 115-141.

Lima, R. N. (2015). A Janela do Mundo de SimCalc: uma possibilidade para o ensino do conceito de função. Anais do VI Seminário Internacional de Pesquisa em Educação Matemática. Pirenópolis: Sociedade Brasileira de Educação Matemática.

Lima, R. N., \& Tall, D. (2008). Procedural Embodiment and Magic in Linear Equations. Educational Studies in Mathematics, 67(1), pp. 3-18.

Lima, R. N., Frant, J. B., \& Pereira, J. C. (2014). Narrando Funções: Uma Possibilidade com o Software Simcalc. II Fórum GT06 - SBEM - Educação Matemática: Novas Tecnologias e Educação a Distância. Rio de Janeiro: Sociedade Brasileira de Educação Matemática.

Schroeder, L. T., \& Lester, F. K. (1989). Developing Understanding in Mathematics via Problem Solving. Em P. Trafton (Ed.), New directions for elementary school mathematics (pp. 3142). Reston, VA: NCTM. 
Tall, D. (2013). How Humans Learn to Think Mathematically: Exploring the Three Worlds of Mathematics (1a ed.). New York, NY, USA: Cambridge University Press.

Submetido em: $17 / 10 / 2018$ Aceito em: 28/05/2019 